\section{Effect of vitamin D on serum markers of bone turnover in SLE in a randomised controlled trial}

\author{
Sara K. Tedeschi, ${ }^{01,2}$ Cynthia Aranow, ${ }^{3}$ Diane L. Kamen, ${ }^{4}$ Meryl LeBoff, ${ }^{2,5}$ \\ Betty Diamond, ${ }^{\oplus 3}$ Karen H. Costenbader ${ }^{1,2}$
}

To cite: Tedeschi SK, Aranow C Kamen DL, et al. Effect of vitamin $D$ on serum markers of bone turnover in SLE in a randomised controlled trial. Lupus Science \& Medicine 2019;6:e000352. doi:10.1136/ lupus-2019-000352

- Additional material is published online only. To view please visit the journal online (http://dx.doi.org/10.1136/ lupus-2019-000352).

Received 17 July 2019 Revised 9 August 2019 Accepted 30 August 2019

\section{Check for updates}

(c) Author(s) (or their employer(s)) 2019. Re-use permitted under CC BY-NC. No commercial re-use. See rights and permissions. Published by BMJ.

${ }^{1}$ Division of Rheumatology, Inflammation, and Immunity, Brigham and Women's Hospital, Boston, Massachusetts, USA ${ }^{2}$ Department of Medicine, Harvard Medical School, Boston Massachusetts, USA

${ }^{3}$ Center for Autoimmune,

Musculoskeletal and

Hematopoietic Diseases,

Feinstein Institute for Medical Research, Manhasset, New

York, USA

${ }^{4}$ Division of Rheumatology, Medical University of South Carolina, Charleston, South Carolina, USA

${ }^{5}$ Division of Endocrinology, Brigham and Women's Hospital, Boston, Massachusetts, USA

Correspondence to

Dr Sara K. Tedeschi;

stedeschi1@partners.org

\section{ABSTRACT}

Objective Bone health in SLE is adversely affected by vitamin $D$ deficiency, inflammatory cytokines and glucocorticoid use. We hypothesised that vitamin D supplementation would increase markers of bone formation and decrease markers of bone resorption in SLE subjects.

Methods We studied 43 vitamin D-deficient SLE subjects who participated in a 12-week randomised controlled trial of 2000-4000 IU/day vitamin D supplementation versus placebo. Subjects had inactive SLE (SLE Disease Activity Index $\leq 4$ ) and were taking $<20 \mathrm{mg}$ prednisone daily at baseline. We assayed baseline and week 12 serum 25-hydroxyvitamin D, N-terminal propeptide of type 1 collagen (P1NP) and C-telopeptide (CTX). We tested the effect of vitamin $D$ versus placebo on change $(\Delta)$ in P1NP and $\triangle \mathrm{CTX}$ in an intention-to-treat analysis. Secondary analyses evaluated whether vitamin $D$ affected bone turnover among subjects achieving vitamin $D$ repletion ( $\geq 30 \mathrm{ng} / \mathrm{mL}$ ) or currently taking glucocorticoids.

Results 28 subjects were randomised to vitamin D and 15 to placebo. Mean age was 39 years and $40 \%$ were using glucocorticoids at enrolment. Repletion was achieved by $46 \%$ in the vitamin $\mathrm{D}$ group versus none in the placebo group. Changes in bone turnover markers were not significantly different in the vitamin $D$ group versus placebo group (median $\triangle \mathrm{P} 1 \mathrm{NP}-0.2$ vitamin $\mathrm{D}$ group vs -1.1 placebo group $(\mathrm{p}=0.83)$; median $\triangle \mathrm{CTX}+3.5$ vitamin $D$ group vs -37.0 placebo group $(p=0.50)$ ). The effect of vitamin $D$ did not differ based on achieving vitamin $D$ repletion or baseline glucocorticoid use.

Conclusion Vitamin D supplementation did not affect the 12-week change in bone turnover markers among SLE subjects in this trial.

\section{INTRODUCTION}

Poor bone health is common in SLE due to disease and treatment. Patients with SLE have twice the fracture risk of individuals without SLE, and patients with SLE with nephritis are at even greater risk. ${ }^{1-3}$ Systemic inflammation, glucocorticoid use, lupus nephritis, premature menopause and vitamin D deficiency all have deleterious effects on bone health. Numerous studies have demonstrated that lower vitamin D levels are associated with higher SLE disease activity, although trials of vitamin D supplementation for reducing SLE disease activity have had conflicting results. ${ }^{4-7}$ Data on vitamin D supplementation for bone health in SLE are mostly derived from observational studies, raising concerns about confounding by indication; patients with SLE perceived to be at highest risk for fracture may be more likely to receive vitamin D.

Circulating vitamin D affects bone metabolism through direct effects on bone and by influencing intestinal calcium absorption and parathyroid hormone (PTH) levels. ${ }^{8}$ Bone resorption by osteoclasts and bone formation by osteoblasts are coupled, such that an increase in bone resorption is followed by an increase in bone formation. The dynamic processes of bone resorption and formation can be measured using biomarkers of bone turnover. The International Osteoporosis Foundation recommends using N-terminal propeptide of type 1 collagen $(\mathrm{P} 1 \mathrm{NP})$ as a marker of bone formation and C-telopeptide (CTX) as a marker of bone resorption in clinical research. ${ }^{9}$ In the setting of vitamin D deficiency, calcium absorption decreases and PTH level increases, leading to increased bone resorption paired with increased bone formation. Vitamin D repletion is expected to increase calcium absorption and decrease PTH level, thereby decreasing both bone resorption (eg, decreasing the level of CTX) and formation (eg, decreasing the level of P1NP).

Limited data from cross-sectional studies in SLE suggests that higher vitamin D levels ${ }^{10}$ and lower SLE disease activity ${ }^{10}$ are associated with higher levels of bone formation markers. Due to their observational nature, past studies that focused on vitamin D deficiency in SLE have been unable to test whether vitamin $\mathrm{D}$ repletion decreases bone turnover.

We investigated the effect of vitamin D supplementation on changes in bone turnover 
markers in a randomised controlled trial in vitamin D-deficient patients with SLE. We hypothesised that vitamin D supplementation would lead to a greater decrease in P1NP and CTX levels compared with placebo.

\section{METHODS}

\section{Study population}

Subjects had completed a randomised, double-blinded, placebo-controlled trial testing the effect of vitamin D3 supplementation on expression of genes induced by interferon-alpha ('interferon gene signature') in patients with SLE (NCT00710021). ${ }^{6}$ The primary outcome was a reduction in the interferon gene signature at week 12. Fifty-seven SLE subjects were randomised at six US sites from 2009 to 2011; 54 subjects were included in a modified intention-to-treat analysis (three subjects never received a dose of study drug). Stored blood samples were available for the current study for 43 subjects (28 in vitamin $\mathrm{D}$ intervention arms and 15 in placebo arm).

\section{Enrolment criteria}

Female and male patients aged $\geq 18$ years who fulfilled American College of Rheumatology 1997 classification criteria for SLE were recruited. Vitamin D deficiency (serum 25-hydroxyvitamin D $(25(\mathrm{OH}) \mathrm{D}) \leq 20 \mathrm{ng} / \mathrm{mL})$ was required. Stable, inactive SLE (Safety of Estrogens in Lupus Erythematosus National Assessment (SELENA)-SLE Disease Activity Index $($ SLEDAI) $\leq 4),{ }^{11}$ prednisone $<20 \mathrm{mg} /$ day or no prednisone and a stable immunosuppressant regimen were required. Exclusion criteria are listed in the online supplementary 1.

\section{Treatment groups}

Subjects were randomised 1:1:1 to vitamin D $2000 \mathrm{IU} /$ day, $4000 \mathrm{IU} /$ day or placebo. Due to limited sample size, subjects randomised to vitamin D $2000 \mathrm{IU} /$ day or $4000 \mathrm{IU} /$ day were analysed together to maximise statistical efficiency. Treatment adherence was assessed at week 12: vitamin D repletion (serum $25(\mathrm{OH}) \mathrm{D} \geq 30 \mathrm{ng}$ / $\mathrm{mL}$ ) was considered evidence of adherence to vitamin $\mathrm{D}$ or non-adherence to placebo.

\section{Study visits and data collection}

Eligibility was confirmed at a screening visit including a blood draw, medical history, medication review and physical examination. Study visits at baseline and week 12 included a blood draw, medical history, medication review, questions about symptoms and physical examination. SLE disease activity was measured at each visit using the SELENA-SLEDAI, modified to include spot urine protein/creatinine ratio. Rho, Inc. managed data collection and quality control.

\section{Laboratory evaluation}

Serum 25(OH)D was measured in baseline and week 12 samples centrally at the Medical University of South Carolina (Hollis laboratory) using a radioimmunoassay (DiaSorin, Stillwater, Minnesota, USA) ${ }^{12}$
Expression of three genes induced by interferon-alpha (Mx1, Ifit1 and Ifi44) at baseline and week 12 was determined using reverse transcription-PCR (TaqMan assay) performed at Feinstein Institute for Medical Research (Diamond laboratory) on whole blood collected using Pax gene tubes. Interferon gene signature was computed relative to expression of these genes in healthy controls. ${ }^{6}$

Bone turnover markers, P1NP and CTX, were measured at the Brigham and Women's Hospital Research Assay Core using excess baseline and week 12 blood samples that had been stored at $-80^{\circ} \mathrm{C}$ at Feinstein Institute for Medical Research (Biorepository). P1NP and CTX were measured in serum with one exception noted in online supplementary file 2. P1NP was measured by radioimmunoassay (Orion Diagnostics, Finland) with intra-assay coefficient of variation (CV) $3.2 \%-7.1 \%$. CTX was measured by immunoradiometric assay (Serum CrossLaps, Arizona, USA) with intra-assay CV 1.8\%-5.0\%. See online supplementary 2 for further details.

\section{Statistical analysis}

Changes $(\Delta)$ in $25(\mathrm{OH}) \mathrm{D}, \mathrm{P} 1 \mathrm{NP}$ and CTX were calculated as week 12 minus baseline value. We estimated correlations between baseline $25(\mathrm{OH}) \mathrm{D}$ and bone turnover markers, and correlations between $\Delta 25(\mathrm{OH}) \mathrm{D}$ and changes in bone turnover markers, $\triangle \mathrm{P} 1 \mathrm{NP}$ and $\triangle \mathrm{CTX}$, using Spearman coefficients. Change in $25(\mathrm{OH}) \mathrm{D}, \mathrm{P} 1 \mathrm{NP}$ and CTX within each study arm was evaluated using signed rank tests. We tested the effect of vitamin D supplementation versus placebo on $\triangle \mathrm{P} 1 \mathrm{NP}$ and $\triangle \mathrm{CTX}$ using Wilcoxon rank-sum tests in an intention-to-treat analysis. We performed several sensitivity analyses testing (1) if $\triangle \mathrm{P} 1 \mathrm{NP}$ and $\triangle \mathrm{CTX}$ differed across the three original study arms, (2) whether achieving vitamin $\mathrm{D}$ repletion versus not affected changes in bone turnover markers and (3) the effect of vitamin $\mathrm{D}$ in subgroups by baseline glucocorticoid use (any/none) and baseline interferon-alpha gene signature (detectable/undetectable). The final sensitivity analysis excluded subjects taking bisphosphonates at baseline.

Analyses were performed using SAS V.9.4. A two-tailed $p$ value $<0.05$ was considered statistically significant.

\section{RESULTS}

We analysed results from 43 subjects: 28 randomised to vitamin D (2000 or $4000 \mathrm{IU} /$ day) and 15 randomised to placebo (see online supplementary 3 ). Black race, the presence of a detectable interferon gene signature and glucocorticoid use were more common among subjects randomised to vitamin $\mathrm{D}$ (table 1 ).

Among all subjects, baseline $25(\mathrm{OH}) \mathrm{D}$ was inversely correlated with baseline P1NP $(\mathrm{r}=-0.31, \mathrm{p}=0.04)$ but not with baseline CTX ( $r=-0.07, p=0.68)$. Twelve-week change in $25(\mathrm{OH}) \mathrm{D}$ was not significantly correlated with $\triangle \mathrm{P} 1 \mathrm{NP}$ $(\mathrm{r}=0.003, \mathrm{p}=0.99)$ or $\Delta$ CTX $(\mathrm{r}=0.07, \mathrm{p}=0.64)$.

Vitamin D significantly increased among subjects in the vitamin D group; subjects in the placebo group also had 
Table 1 Baseline characteristics of SLE subjects in a randomised trial of vitamin $D$ versus placebo

\begin{tabular}{|c|c|c|}
\hline & Vitamin $D^{*}(n=28)$ & Placebo $(n=15)$ \\
\hline \multicolumn{3}{|l|}{ Demographics } \\
\hline Age, years & $34.5(29.5-45.0)$ & $37.0(30.0-50.0)$ \\
\hline Female & 92.9 & 93.3 \\
\hline \multicolumn{3}{|l|}{ Race } \\
\hline White & 32.1 & 60.0 \\
\hline Black & 53.6 & 40.0 \\
\hline Other & 14.3 & 0 \\
\hline \multicolumn{3}{|l|}{ SLE characteristics } \\
\hline Disease duration, years & $8.0(3.9-14.2)$ & $10.0(3.3-16.0)$ \\
\hline ANA positive & 96.4 & 86.7 \\
\hline $\begin{array}{l}\text { Anti-double stranded DNA } \\
\text { positive }\end{array}$ & 92.9 & 93.3 \\
\hline Renal disorder & 35.7 & 40.0 \\
\hline SELENA-SLEDAI score & $3(2-4)$ & $4(2-4)$ \\
\hline $\begin{array}{l}\text { Interferon gene signature } \\
\text { detectable }\end{array}$ & 89.3 & 73.3 \\
\hline \multicolumn{3}{|l|}{ Laboratory values } \\
\hline CTX, mg/L & $80.0(34.0-118.5)$ & $76.0(64.0-147.0)$ \\
\hline $\mathrm{P} 1 \mathrm{NP}, \mu \mathrm{g} / \mathrm{L}$ & $45.2(31.8-62.2)$ & $48.9(31.5-74.3)$ \\
\hline $\begin{array}{l}\text { Serum } 25 \text {-hydroxyvitamin } D \text {, } \\
\mathrm{ng} / \mathrm{mL}\end{array}$ & $11.9(10.1-14.4)$ & $9.9(6.9-14.5)$ \\
\hline \multicolumn{3}{|l|}{ Medications } \\
\hline \multicolumn{3}{|c|}{ Glucocorticoids, prednisone equivalent } \\
\hline $0 \mathrm{mg} /$ day & 57.1 & 66.7 \\
\hline$>0$ to $<7.5 \mathrm{mg} /$ day & 25.0 & 20.0 \\
\hline$\geq 7.5 \mathrm{mg} / \mathrm{day}$ & 17.9 & 13.3 \\
\hline Antimalarial & 60.7 & 80.0 \\
\hline Azathioprine & 25.0 & 6.7 \\
\hline Methotrexate & 14.3 & 0 \\
\hline Mycophenolate & 32.1 & 33.3 \\
\hline Bisphosphonate & 10.7 & 6.7 \\
\hline
\end{tabular}

Presented as median (IQR) or \%.

*2000 IU daily (low dose) or 4000 IU daily (high dose).

CTX, C-telopeptide; P1NP, N-terminal propeptide of type 1 collagen; SELENA-SLEDAI, Safety of Estrogens in Lupus National Assessment-SLE Disease Activity Index.

a significant but smaller increase in vitamin D (figure 1A). The median increase in $25(\mathrm{OH}) \mathrm{D}$ was significantly greater among subjects in the vitamin D group (16.9 (IQR 13.821.0) $\mathrm{ng} / \mathrm{mL}$ ) than placebo (4.4 (IQR -1.3 to 6.6$) \mathrm{ng} /$ $\mathrm{mL})(\mathrm{p}<0.01)$. Median P1NP did not significantly change between baseline and week 12 in the vitamin $\mathrm{D}$ or placebo group, and the between-group difference was not significant (figure 1B). Likewise, median CTX was not significantly different at baseline and week 12 in either group, and the between-group difference was not significant (figure 1C). The online supplementary 4 presents individual-level data.

Changes in bone turnover markers were similar in the three original study arms (table 2). Changes in P1NP and CTX were similar among 13 subjects who achieved versus 30 who did not achieve vitamin $\mathrm{D}$ repletion. In analyses stratified by baseline glucocorticoid use, we did not observe a difference in $\triangle \mathrm{P} 1 \mathrm{NP}$ or $\triangle \mathrm{CTX}$ in the vitamin $\mathrm{D}$
A Change in $25(\mathrm{OH})$ vitamin D $\quad \square$ baseline

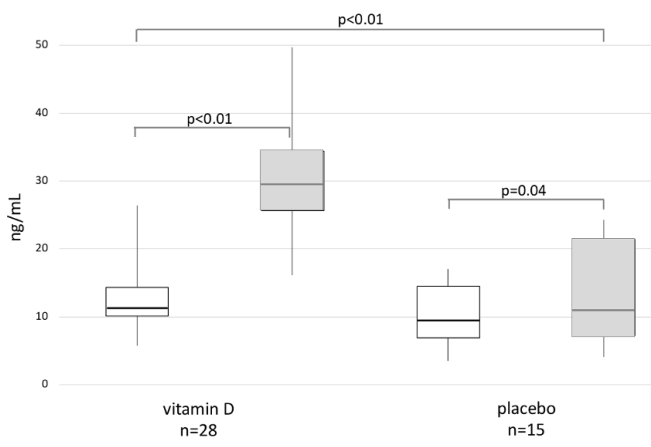

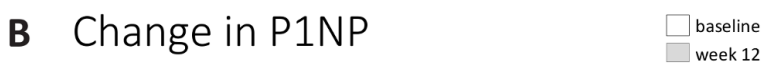
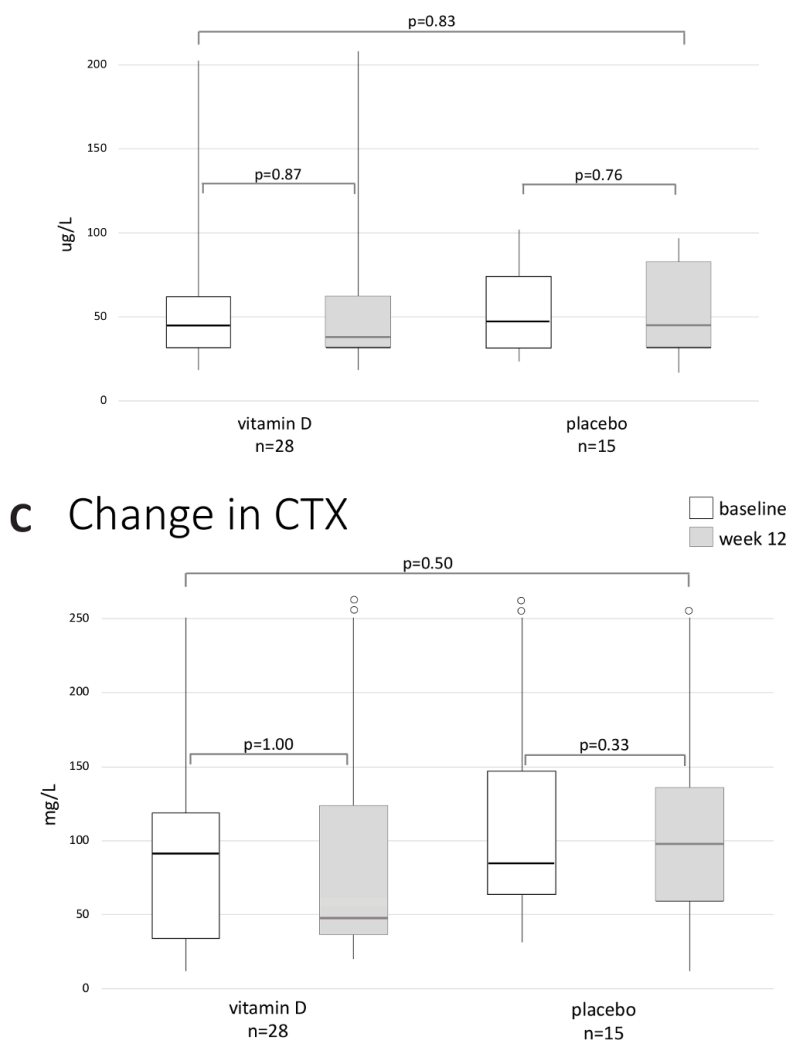

Figure 1 Within-group and between-group change in $(A)$ 25-hydroxyvitamin D (25(OH)D), (B) N-terminal propeptide of type 1 collagen (P1NP) and (C) C-telopeptide (CTX) from baseline to week 12 .

versus placebo group. Changes in bone turnover markers did not differ by vitamin D versus placebo group among subjects with or without a detectable interferon signature at baseline. Results were similar after excluding four subjects using bisphosphonates at baseline.

\section{DISCUSSION}

In this randomised, placebo-controlled trial in vitamin D-deficient SLE subjects, we observed small changes in P1NP and CTX at 12 weeks in the vitamin D and placebo groups. Baseline serum 25(OH)D was inversely associated with baseline P1NP, but change in $25(\mathrm{OH}) \mathrm{D}$ at 12 weeks was not correlated with change in bone turnover markers. 
Table 2 Sensitivity analyses

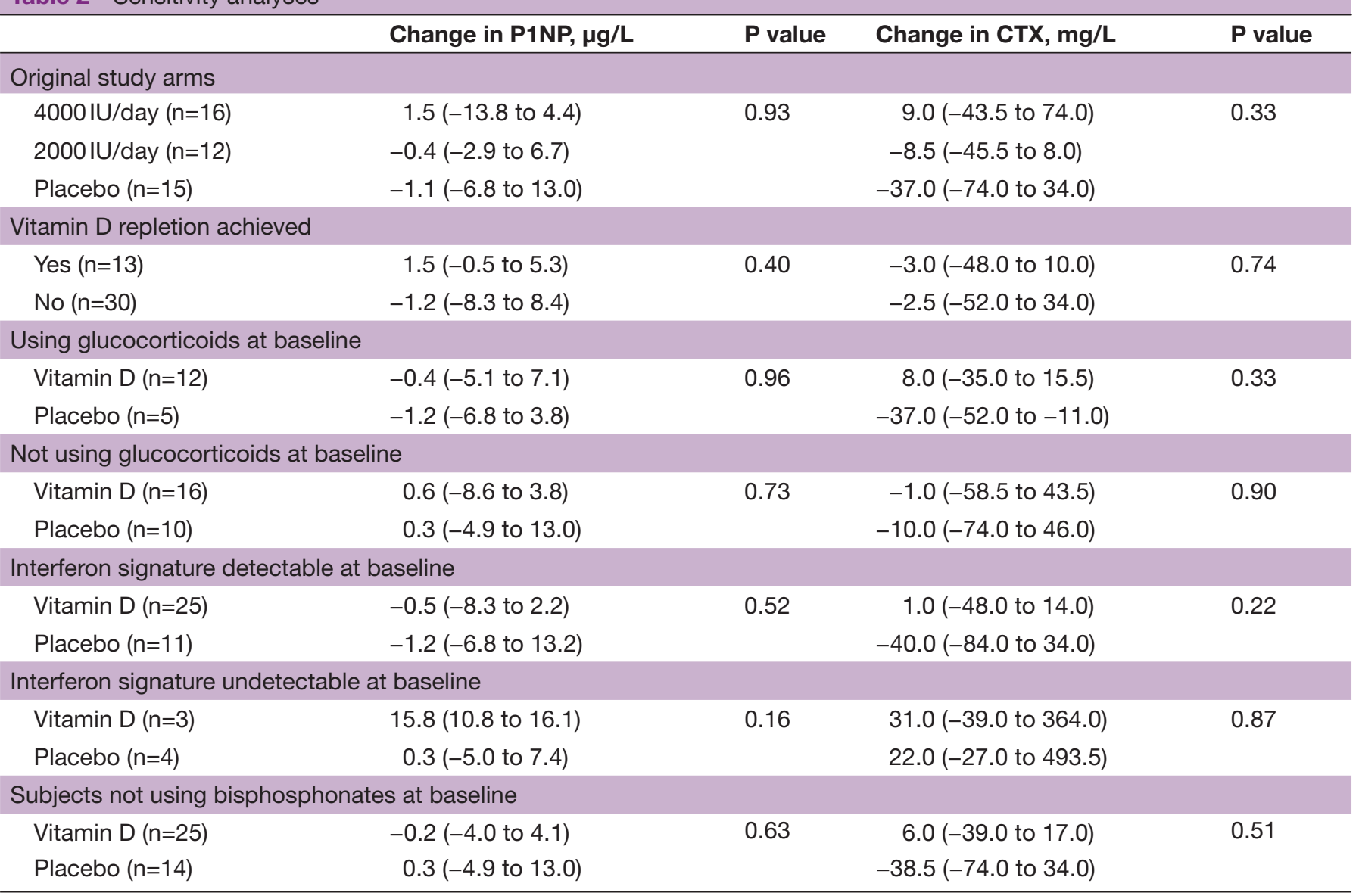

$\mathrm{P}$ values from Kruskal-Wallis test for three-group comparison and Wilcoxon rank-sum test for two-group comparisons.

Changes in P1NP and CTX were similar in the vitamin $\mathrm{D}$ and placebo groups in analyses stratified by vitamin $\mathrm{D}$ repletion, baseline glucocorticoid use and baseline interferon-alpha gene signature.

Bone turnover markers are useful endpoints for clinical research studies because they change more rapidly than bone mineral density in response to bone-active therapies. ${ }^{13}$ They generally increase or decrease together due to the homeostatic relationship between bone formation and resorption. Glucocorticoid use disrupts this homeostasis, leading to predominantly decreased bone formation and possibly increased bone resorption..$^{14}$ Therefore, it is possible that the effect of vitamin $\mathrm{D}$ on bone turnover markers differs in patients using versus not using glucocorticoids. We did not observe a differential effect of vitamin D versus placebo based on glucocorticoid use, though the small sample size limited our ability to draw definitive conclusions. See online supplementary 5 for further context.

Our study had several strengths, including a randomised, double-blind, placebo-controlled design among patients with SLE with similar renal function (serum creatinine $\leq 1.5 \mathrm{mg} / \mathrm{dL}$ ), pertinent to P1NP and CTX assays. All subjects were aged $<50$ years, corresponding with premenopausal years among female subjects. We measured P1NP and CTX, the bone turnover markers recommended by the International Osteoporosis Foundation for use in clinical trials.

Our study had important limitations, including the short duration and limited sample size. As the study population was small, the study lacked statistical power for definitive conclusions. Not all subjects consented to secondary use of their blood samples and banked blood sample quantity was insufficient for some; thus, serum biomarkers from 11 trial participants were not assayed. Subjects were recruited across all seasons so seasonal variation in endogenous vitamin $\mathrm{D}$ synthesis might have affected the results, particularly the increase in vitamin D in the placebo group. Both female and male SLE subjects were included; sex-based differences in bone metabolism may have impacted our results. Participants had stable, inactive SLE and our results may not generalise to patients with high SLE disease activity.

We did not observe a significant decrease in bone turnover markers in the vitamin D group compared with placebo overall or in the small subgroup using glucocorticoids at baseline. However, this subgroup analysis (and likely the overall analysis) was underpowered due to small sample size, allowing the possibility that an effect of vitamin $\mathrm{D}$ on bone turnover markers was not observed even if a true effect exists. We advise that patients with SLE and their clinicians continue to follow the American 
College of Rheumatology's Glucocorticoid-Induced Osteoporosis guidelines, which include optimising vitamin D intake, as the current study was not designed to investigate bone density or fracture outcomes. ${ }^{15}{ }^{16}$ A larger, longer-term trial of vitamin $\mathrm{D}$ versus placebo in patients with SLE - particularly premenopausal women with high disease activity-using bone mineral density or bone microarchitecture as outcomes would help guide clinical care.

\section{CONCLUSIONS}

In this small randomised trial in vitamin D-deficient patients with SLE, we did not observe a change in P1NP or CTX at 12 weeks in subjects randomised to vitamin D 2000-4000 IU/day versus placebo. Larger trials in premenopausal, vitamin D-deficient patients with SLE focused on changes in bone mineral density or bone microarchitecture could elucidate the effect of vitamin D supplementation in this population with increased fracture risks.

Acknowledgements The authors would like to acknowledge the following abstract presented in 2018: https://acrabstracts.org/abstract/effect-of-vitamin-d-on-serummarkers-of-bone-turnoverin-sle-in-a-randomized-controlled-trial/.

Contributors All authors contributed to the study design, interpreted results and approved the final version of the manuscript. SKT, CA, DLK, BD and KC contributed to data collection and analysis. SKT drafted the initial version of the manuscript.

Funding This work was supported by the Lupus Foundation of America Career Development Award, the National Institutes of Health Autoimmunity Centers of Excellence grants U19-Al056363 and U19-Al-0563626, and the National Institute of Arthritis, Musculoskeletal and Skin Diseases K24 AR066109, K24 AR068406, and K23 AR075070.

Competing interests None declared.

Patient consent for publication Not required.

Ethics approval The Institutional Review Board of each study site approved the trial. The Partners HealthCare Institutional Review Board approved all aspects of this study (protocol 2016P002461), which included subjects who had specifically consented for their data to be used in future research.

Provenance and peer review Not commissioned; externally peer reviewed.

Open access This is an open access article distributed in accordance with the Creative Commons Attribution Non Commercial (CC BY-NC 4.0) license, which permits others to distribute, remix, adapt, build upon this work non-commercially, and license their derivative works on different terms, provided the original work is properly cited, appropriate credit is given, any changes made indicated, and the use is non-commercial. See: http://creativecommons.org/licenses/by-nc/4.0/.

\section{REFERENCES}

1. Tedeschi SK, Kim SC, Guan H, et al. Comparative fracture risks among United States medicaid enrollees with and those without systemic lupus erythematosus. Arthritis Rheumatol 2019;71:1141-6.

2. Bultink IEM, Harvey NC, Lalmohamed A, et al. Elevated risk of clinical fractures and associated risk factors in patients with systemic lupus erythematosus versus matched controls: a population-based study in the United Kingdom. Osteoporos Int 2014;25:1275-83.

3. Wang S-H, Chang Y-S, Liu C-J, et al. Association of systemic lupus erythematosus with a higher risk of cervical but not trochanteric hip fracture: a nationwide population-based study. Arthritis Care Res 2013;65:1674-81.

4. Salman-Monte TC, Torrente-Segarra V, Vega-Vidal AL, et al. Bone mineral density and vitamin $\mathrm{D}$ status in systemic lupus erythematosus (SLE): a systematic review. Autoimmun Rev 2017;16:1155-9.

5. Andreoli L, Dall'Ara F, Piantoni S, et al. A 24-month prospective study on the efficacy and safety of two different monthly regimens of vitamin D supplementation in pre-menopausal women with systemic lupus erythematosus. Lupus 2015;24:499-506.

6. Aranow C, Kamen DL, Dall'Era M, et al. Randomized, double-blind, placebo-controlled trial of the effect of vitamin D3 on the interferon signature in patients with systemic lupus erythematosus. Arthritis Rheumatol 2015;67:1848-57.

7. Lima GL, Paupitz J, Aikawa NE, et al. Vitamin D supplementation in adolescents and young adults with juvenile systemic lupus erythematosus for improvement in disease activity and fatigue scores: a randomized, double-blind, placebo-controlled trial. Arthritis Care Res 2016;68:91-8.

8. Holick MF. Osteomalacia and rickets. In: Hochberg MC, ed. Rheumatology. 6th edn. Philadelphia: Elsevier, 2015: 1680.

9. Vasikaran $\mathrm{S}$, Eastell R, Bruyère $\mathrm{O}$, et al. Markers of bone turnover for the prediction of fracture risk and monitoring of osteoporosis treatment: a need for international reference standards. Osteoporos Int 2011;22:391-420.

10. Sarkissian A, Sivaraman V, Bout-Tabaku S, et al. Bone turnover markers in relation to vitamin $D$ status and disease activity in adults with systemic lupus erythematosus. Lupus 2019;28:156-62.

11. Petri M, Kim MY, Kalunian KC, et al. Combined oral contraceptives in women with systemic lupus erythematosus. $N$ Engl $J$ Med 2005;353:2550-8.

12. Hollis BW, Kamerud JQ, Selvaag SR, et al. Determination of vitamin D status by radioimmunoassay with an 125l-labeled tracer. Clin Chem 1993;39:529-33.

13. Bauer DC, Black DM, Bouxsein ML, et al. Treatment-related changes in bone turnover and fracture risk reduction in clinical trials of anti-resorptive drugs: a meta-regression. J Bone Miner Res 2018;33:634-42.

14. Lau AN, Sambrook PN, Adachi JD. Glucocorticoid-induced osteoporosis. In: Hochberg M, ed. Rheumatology. 6th edn. Philadelphia: Elsevier, 2015: 1674.

15. Grossman JM, Gordon R, Ranganath VK, et al. American College of rheumatology 2010 recommendations for the prevention and treatment of glucocorticoid-induced osteoporosis. Arthritis Care Res 2010;62:1515-26.

16. Buckley L, Guyatt G, Fink HA, et al. 2017 American College of rheumatology guideline for the prevention and treatment of glucocorticoid-induced osteoporosis. Arthritis Rheumatol 2017;69:1521-37. 